\title{
Swimming with the Tide: Adapting to Long-Term Imprisonment
}

Ben Crewe, Susie Hulley and Serena Wright

\begin{abstract}
Given the increasing number of prisoners serving life sentences in England and Wales, and the increasing average length of these sentences, it is surprising that so little attention has been paid to the experiences and effects of such sanctions. This article describes how prisoners serving very long sentences from an early age adapt over time to their circumstances. In particular, it focuses on the transition between the early and subsequent stages of such sentences, specifically, the ways that these prisoners adapt to the sentence, find means of managing time, come to terms with their offense, shift their conception of control and self-control, make their sentence constructive, and find wider meaning in and from their predicament. Our argument is that most prisoners demonstrate a shift from a form of agency that is reactive to one that is more productive, as they learn to 'swim with', rather than against, the tide of their situation.
\end{abstract}

Keywords Long-term imprisonment. prisoners. adaptation. transitions.

In a recently published article, Kazemian and Travis (2015:3) argue that researchers and policy makers have 'largely ignored the issue of long termers and lifers', and, more specifically, that 'life course and criminal career research has failed to examine and document changes that occur during periods of incarceration' (p4). Writing primarily about the US - the global leader in the allocation of very long sentences - and about particular kinds of research approaches, their diagnosis is relevant beyond these geographic and methodological domains. As they note, 'the most comprehensive studies conducted with long 
termers and lifers were carried out several decades ago' (p8), a statement that applies to the UK and Western Europe as much as it does to North America. In the latter, researchers who are interested in extreme forms of confinement can turn their attention to super-max institutions and the phenomenon of life without parole sentences (see, for example Rhodes 2004; Johnson and McGunigall-Smith 2008). In England and Wales, given the rising number of prisoners serving life sentences, and the increasing average length of these sentences, it is all the more surprising that so little attention has been paid to these sanctions. Changes in legislation have increased the 'starting points' for consideration of the minimum period of custody for a range of homicide offenses. As a result, the average tariff imposed upon people sentenced to life (excluding whole life sentences) increased from 12.5 to 21.1 years between 2003 and 2013. ${ }^{1}$ In sum, an increasing number of men and women are serving sentences which, until fairly recently, were not only extremely uncommon, but were also considered more or less unsurvivable.

While Kazemian and Travis discuss long-term prisoners primarily in relation to their criminal careers and potential desistance, writing within the tradition of mainstream prison sociology, our interest does not need to be limited to these parameters. Large numbers of men and women face decades of incarceration, and we should therefore be interested - for both humanistic and sociological reasons - in the ways that they cope with their predicament and seek to construct a life for themselves in their new world. Such matters are the focus of this article, which describes how prisoners serving very long sentences from an early age adapt over time to their circumstances.

\section{Literature Review}

\footnotetext{
${ }^{1}$ Information obtained from Ministry of Justice by Jonathan Bild, Faculty of Law, University of Cambridge - Freedom of Information request FOI/89346, April 2014
} 
In their introduction to The Effects of Imprisonment, Liebling and Maruna (2005) outline some of the limitations of the prison effects literature. The prevailing paradigm, they note, asserts that the adaptive responses of prisoners are 'basically invariant' (p2) and that prisoners are in effect impervious to the impact of incarceration. Such assumptions rest, in part, on measurements of harm that are highly partial, failing to take into account the 'affective dimension' (p3) of imprisonment, such as feelings of loneliness and injustice, whose effects might surface indirectly or at points in time well after release from prison (cf. Grounds 2005; Liem and Kunst 2013). As Liebling and Maruna contend (p3), these concealed but ubiquitous aspects of the prison experience 'have not been measured or taken seriously enough by those interested in the question of prison effects'.

To some degree, disagreements about the effects of confinement reflect differences in the methodological and conceptual commitments of psychologists and sociologists, the former focussing on quantifiable measures and the latter on experiential description. These differences are particularly apparent in the literature on long-term imprisonment, which has often been the focus of the effects literature generally, because of an assumption that any effects are likely to deepen over longer periods of time. Thus, while there are inconsistencies within quantitative studies of long-term confinement, the broad conclusion that can be drawn from such research (both cross-sectional and longitudinal) is that extended periods of incarceration do not appear to have a debilitating impact on such matters as cognitive functioning or self-esteem (inter alia, Banister, Smith, Heskin and Bolton 1973; MacKenzie and Goodstein 1985; Rasch 1981), and that, if anything, the problems of imprisonment seem to be less rather than more severe among prisoners who are further into their sentences 
(Richards 1978; Flanagan 1980; Leigey and Ryder 2014; but see XXXX for an alternative interpretation of such findings).

In an explicit critique of studies of this kind, Cohen and Taylor (1972: 39) comment drily that the long-term prisoners whom they studied:

...did not mention shifts in introversion-extraversion when we spoke to them ... Neither did they discuss decline in skills or changes in reaction time .... They were peculiarly obsessive, however, in their conversation about such mundane and untested matters as the passage of time, the making and breaking of friends, the fear of deterioration, the role of self-consciousness and the loss of identity.

Here, then, the critique relates both to the variables under assessment and an approach that appears to position the long-term prisoner as a kind of research 'specimen'. Cohen and Taylor's landmark research was not without its own limitations, but it highlighted the profound existential implications of prolonged confinement and the ways in which life sentenced prisoners reflected in an ongoing and agentic way on their predicament and how to endure it. Even more noticeably, aligning itself with autobiographical accounts of 'survival in extreme situations' (the title of the book's second chapter), their study provided a textured account of how long-term imprisonment was subjectively experienced and how prisoners found means of adapting to their circumstances.

A range of other (qualitative or mixed-methods) studies provide similar forms of insight, and tend to emphasize a number of key themes. The first of these is time. As many scholars note (Cohen and Taylor 1972; Sapsford 1983; Cope 2003; O'Donnell 2014), time is the essence of 
any term of coercive confinement, and, as Flanagan (1981:212) emphasizes, 'the element of time exacerbates all of the deprivations [of prison life] and transforms them ... into major problems of survival'. Long sentences have a distortive effect on the way that time is normally experienced, as O’Donnell (2014) describes with specific reference to solitary confinement. While time in prison feels endless, empty and unreal (a 'misty abyss', to quote Cohen and Taylor 1972: 95; see also Jewkes 2005; O'Donnell 2014) - something to try to deplete - the long-term prisoner remains aware that time outside the prison is all too precious (Jamieson and Grounds 2005). Meanwhile, among the greatest struggles of prisoners serving long, indeterminate sentences is the overwhelming nature of the time that lies ahead of them, which may feel impossible to contemplate (Cohen and Taylor 1972; Flanagan 1981; Liebling, Arnold and Straub 2012). O'Donnell (2014: 178) argues that since 'the currency of the past is soon spent', and thoughts of the future generate anxiety, prisoners instead focus on and live within an 'extended present'.

A second theme in studies of long-term prisoners is the struggle to find meaning and purpose, and to cushion the self against the assault of institutional life. Sapsford (1983: 77) notes that 'The prisoner has to live with potentially no sense of direction, movement or purpose, which is a constraint beyond the scope of our culture's repertoire of normal-life adaptations'. Receiving a life sentence may be experienced as a kind of 'bereavement for oneself' (Jewkes 2005: 370), and prisoners serving very long sentences may undergo a deep existential crisis, overwhelmed by a sense of hopelessness and despair about their predicament (Liebling 2014: $5)$.

A third theme is that of shame, remorse and redemption. Toch (2010) speculates that many serious and long-term offenders come to feel themselves to be substantially different from the 
person they were at the point that they committed their index offense. Some undergo 'crucial regenerative change pretty much on their own' (p8), and - as Irwin (2009) also describes many narrate sincere scripts of redemption, which come to dominate their orientation both to life in prison and post-release (see also Schinkel 2014).

A final theme - though we make no claim that these are exhaustive, since there is much to be said about the maintenance of external relationships, for example - is that of coping, adaptation and change. Sustained imprisonment may only be survivable with the support of some kind of protective ideology (Cohen and Taylor 1972) or - conversely - through acquiescence to the terms and parameters of the sentence (Schinkel 2014). Jewkes (2005) draws on the idea of liminality to describe the state of social limbo that long-term prisoners occupy, when detached from both their past and from a predictable future. As Jewkes goes on to argue, though, this sense of ambiguity is eventually supplanted, as prisoners 'construct new narratives of self' (p376). While those who undergo psychological breakdown, or who take their own lives, are the phantom figures of studies of prisoner coping, what seems apparent from the literature is that most prisoners serving very long sentences not only find strategies for alleviating the difficulties that they encounter, but often attribute positive meaning of some kind to their experience (Schinkel 2014). A number of scholars have highlighted the way in which long-termers exhibit a distinctive attitude of 'maturity', in which they seek to avoid trouble, 'consider alternatives prior to action' (Flangan 1981: 216), adjust to the imposition of authority, and use their time constructively. To quote Johnson and Dobrzanska (2005: 8), 'lifers come grudgingly to accept the prison as their involuntary home for life', accommodating to their situation through personal routines and behaviors that provide a localized sense of autonomy and a sense of wider purpose. In one of the few longitudinal explorations of adaptive behavior among long-term male prisoners - and it 
should be noted that the literature on long-term female prisoners is even sparser (although see Walker and Worrall 2000, and XXXX, in progress) - Zamble (1992: 421) reports that, over time, such men deliberately withdraw 'from the diffuse social networks that are typical of inmate interactions' maintain their emotional ties with people in the community, become more positive in their attitudes towards the criminal justice system, and become progressively more preoccupied with the future. 'In effect, they sometimes seemed to be living within a world of their own, inside the prison but separate and apart from its ordinary discourse ... if their bodies were in prison, their cognitive focus was elsewhere' (p421).

Here, then, the findings of qualitative and quantitative studies are consistent in suggesting that long-term prisoners find ways of coping that make the problems of imprisonment more manageable over time (even if, as XXXX argue, this may come at some cost). Much of the existing literature is, however, somewhat dated, and is based on studies in the United States, whose exceptional commitment to imposing very long sentences is not generalizable throughout the developed world. This article seeks to advance the body of research in this area, drawing on a study of life sentenced prisoners in England and Wales not just to offer insight into the experience of long-term confinement, but to expose the terms and dynamics of personal change, as these men and women adapt to life-changing periods of time behind bars. We begin by focussing on prisoners' general descriptions of adapting to their sentence, which involved recognising the basic need to cope with and 'make the most of' their situation, acknowledging that the prison was now the primary life domain, and reframing and rationalizing the predicament in a positive manner. Based on participants' recollections of their sentences or on differences between the accounts of prisoners at different sentence stages, we go on to detail transitions in four key domains: the perception and management of time, consideration of the offense, the conception of control and self-control, and practices of 
making meaning and finding purpose. In doing so, and drawing on work by Margaret Archer on different modes of reflexivity, we highlight clear differences between the orientations of prisoners at the early and subsequent stages of very long sentences, emphasizing a shift from a form of agency that was essentially backwards-looking and reactive to one which was future-oriented and productive, albeit within the particular parameters of prolonged confinement. While those in the initial years of their sentences felt able to determine their lives in limited ways, within limited spheres, and with limited existential return - in part because they were often exercising agency against the flow of their carceral predicament those who had served longer periods felt more able to shape their lives, within a greater number of domains, and in ways that provided them with greater meaning and fulfilment.

\section{The Study}

The research on which this article is based focused on men and women serving very long life sentences (a minimum/'tariff' period of 15 years or more), sentenced when aged 25 years or younger. ${ }^{2}$ This focus was born out of a concern with the increasing number of prisoners serving very long sentences, in England and Wales particularly, and the absence of research on experiences and consequences of such disposals, both for the offenders themselves and for those who manage them. Data provided by the National Offender Management Service revealed that, at the start of the fieldwork period (in February 2013), there were 789 male prisoners and 29 female in the England and Wales prison system who met these criteria.

\footnotetext{
${ }^{2}$ Prisoners serving 'whole-life tariffs', of whom there are around 60 in England and Wales, were excluded from our sample, since the absence of a possibility of release makes their prison experience quite different from those within our population.
} 
Our fieldwork involved two main methods. The first involved the distribution of a survey, primarily designed to assess the problems of long-term imprisonment, to all prisoners who met our criteria in all of the 24 prisons ( 15 holding male prisoners and nine holding female prisoners) in which we collected data. ${ }^{3}$ The second involved in-depth, semi-structured interviews with 125 men and 21 women within these establishments. Male participants were selected based on a purposive sampling procedure designed to capture prisoners at different sentence stages, in order to explore the ways in which the challenges and experience of longterm confinement might vary according to the phase of the sentence. These sentence stages were determined as follows: Early - less than four years served (at the point at which the study began); Mid - the mid-point of an individual's tariff, plus or minus two years; Late tariff end date minus two years onwards. ${ }^{4}$ Specifically, having received official data from the National Offender Management Service about the location of prisoners who met our criteria, we sampled prisoners at different sentence stages and in different kinds of establishments (i.e. different security-levels) in ways that reflected both the number of prisoners at these stages and in these types of establishment within the overall population. ${ }^{5}$ Interviews were therefore undertaken in a broad range of prisons in which life-sentenced prisoners are accommodated (normally among prisoners serving a range of sentences), including young offender institutions, high-security prisons, and category B, C and D establishments (high/mediumsecurity, medium-security, and open prisons), covering the entire spectrum of prison types within the England and Wales prison system. Due to the relatively low number of women serving very long life sentences from young adulthood at the time of our fieldwork, we sought to interview all those who met our research criteria, regardless of sentence stage. In total, 310 men (39\% of the male population who matched the research criteria) and 23

\footnotetext{
${ }^{3}$ For further information on the design, use, and results of the survey see XXXX 2015). ${ }^{4}$ Mean age at time of interview: early-stage: 22 ; mid-stage: 30 ; late-stage: 46.

${ }^{5}$ Since, to minimise strain on resources, the National Offender Management Service prefers that studies are parsimonious in selecting the overall number of research sites, this was an inexact process.
} 
women ( $79 \%$ of the female population who matched the research criteria) participated in the study either by conducting an in-depth interview, completing a survey, or both. All of our participants had been convicted of murder, and were serving mandatory life sentences. ${ }^{6}$

Interviews were conducted in two parts. The first was a detailed life history interview, which drew heavily on the literature on narrative inquiry and life stories (e.g. Hollway \& Jefferson, 2000; McAdams, 1988) and focused on various aspects of pre-sentence life. Interviewees were not asked directly to disclose the details of their index offense, but they were not discouraged from doing so. The second part of each interview focussed on life inside prison. Our main interests were the particular problems that participants encountered, and their strategies for managing them; their social adaptations (specifically, the relationships they developed with other prisoners and staff); and their thoughts on the legitimacy of their predicament. More specifically the interview schedules covered such areas as the perceived impact of the sentence on personal identity, the most painful and problematic aspects of the sentence, strategies for coping with these problems and with the sentence as a whole, the ways in which relationships with people outside the prison had changed (or endured), the basis and functions of social affiliations inside the prison, the influence of prison staff in shaping the sentence, attitudes towards the institution, the prison system and the broader criminal justice system, and expectations of the future.

Of particular relevance for this article, all participants were asked to reflect at length both on their feelings during the early days and months of their sentence and on the changes in their

${ }^{6}$ Although it is possible to receive a sentence meeting our criteria for a number of offenses, such disposals are very uncommon in England and Wales for offenses other than murder. 
adaptive styles and strategies during the subsequent periods of the sentence. ${ }^{7}$ Much of the material that features in this article derives not just from the responses to these questions, but from general discussion of the experience of the sentence over many years. All interviews were transcribed and coded in full, using an iterative analytic approach, which organized the material using a pre-defined thematic framework while leaving room for the addition and deletion of themes where appropriate. Prisoners' adaptive patterns were relevant to each of these areas, and represent an overarching theme within the research. Those that we identify in this article represent general rather than universal patterns.

\title{
Adapting to the Sentence
}

\begin{abstract}
'A long prison sentence is not $[\ldots]$ a short intermission in the real business of life, it is the real business of life ... one has to either face the fact that one's life was over at the moment of entering the prison, or that one's life is that existence which takes place within the prison' (Cohen and Taylor 1972: 90-1)
\end{abstract}

For the majority of participants, the early phase of the sentence was characterized by bewilderment, anger, denial, and a form of 'temporal vertigo' resulting from consideration of the sheer amount of time in prison that lay ahead (see XXXX, in press). Many prisoners who were further into their sentences continued to harbor underlying feelings of desperation and resentment about their predicament. However, the common view was that, following an

\footnotetext{
${ }^{7}$ Given that a potential methodological weakness of the research is that participants at different sentence stages might not be directly comparable, it is worth noting that there was remarkable consistency between the adaptive experiences described by participants who were currently in the early sentence stage and those who were recalling this period (and, likewise, between those in the middle phase of their sentence and those who were reflecting back on this time). It should also be noted that neither the mean age when sentenced of our early, mid and late-stage interviewees $(20,21$, and 21 respectively), nor their mean tariff lengths $(21.6,19.3$ and 18.7 respectively), differed significantly.
} 
initial period of turmoil, accepting the situation was essential for psychological survival, and 'coping' was unexpectedly achievable:

Maybe it's just me, but there's nothing I can do, I've learnt to accept the sentence.

[...] you just have to still get on with life.

You would drive yourself mad, surely, otherwise, wouldn't you?

Yeah, you would. Then you're looking at things like depression: 'There's no hope for me. What am I going to do with the rest of my life? Is there any point going on?' You get suicidal, and you don't really want to go down that road. (Aaron, 40s, 25-yr tariff, served 24)

When I was on remand, I was chatting to a member of staff, I said 'if I get lifed off I'm going to kill myself because I can't cope, I can't go away for life'. [And] then like literally as soon as I got convicted, it's like a very strange thing, something switches in you where you find this inner strength that you never ever knew you had, this strength comes from nowhere (Jackie, 20s, 22-yr tariff, served 4)

Many interviewees commented along the lines that they were 'here too long to be depressed', and could not afford to let themselves 'get mired down in that kind of thinking', due to the risks of descending into depression, drug use, and other such pathologies. The only option other than coping was not coping and while adjusting to decades of confinement was generally presented as a bleak necessity, it was preferable to psychological disintegration: ${ }^{8}$

\footnotetext{
${ }^{8}$ We have reason to believe that the prisoners who found their predicament too much to bear psychologically might not feature in our sample, since organizational data that we requested revealed that 191 men and women who met the criteria for our study had been transferred to secure psychiatric hospitals during the course of their sentences.
} 
You don't really have much choice. You know, it's like saying 'd'you want to be shot in the head by a gun or d'you want to be stabbed in the heart by a knife?' (Bernard,

\section{0s, 16-yr tariff, served 24)}

You've got two choices when you're faced with a sentence like this: sink or swim, really, and there's a multitude of ways to sink and only one way to swim. (Neil, 30s,

\section{8-yr tariff, served 12)}

Most prisoners who were beyond the first few years of their sentence therefore emphasized the need to make the best of a situation that they now accepted they were in. While opinions varied as to how long it took to 'come to terms' with the sentence, most prisoners recalled that a number of years had passed before they recognized the full implications of their predicament and began to construct a new life for themselves in prison:

It took five years before it hit me [...] I was playing on the computer, and, I don't know, I just started going weird. I couldn't breathe or nothing [...] A lot of lifers probably won't admit it to you, but they do get it.

They get what, sorry?

That moment. It's a feeling of being enclosed, of being unable to love, hug your loved ones .... Your liberty has been taken [...] it's a feeling of being alone. ${ }^{9}$ (Benjamin, 30s, 15-yr tariff, served 14)

\footnotetext{
9 This account is redolent of O'Donnell's (2014: 189-191) description of what Russo (1943, cited in O'Donnell 2014) called 'Chronophobia', a panic that occurs when the prisoner is beyond the distractions of the early phase of the sentence, and comes to consider the time left ahead of him.
} 
For some participants, this period marked the time during which they were appealing their conviction or sentence length, and could therefore suspend the point at which they confronted the years of confinement that lay ahead. Others explained that it was only once they were in a settled prison environment, with other prisoners serving long sentences, that they could commit psychologically to the revised parameters of their existence: 'like decorating your cell. It was in effect: that's my home'. Others still could only confront the time ahead of them once they had a few years 'under their belt' ( Like I've done five years, got thirteen left. I can sort of imagine that amount of time. Before it was fucking overwhelming'). Almost all commented that, after a period of a few years, both friends from and memories of the world outside began to fade, and the stark reality set in that they were 'persons living in prison rather than offenders doing time' (Zamble 1992: 423-4):

I think it hits you after about three or four years [...] it's when you start losing things, when you start losing people, when you start realising life goes on, when people out there start getting married, [...] start progressing in life, and then you sit in here and you think 'right, I wasted my life over what?' (Cary, 20s, 19-yr tariff, served 4)

You start off your sentence and you think about the outside world, things you miss, your family, if you're in a relationship and stuff like that. You do miss that, but then as time goes by, because you have no real contact apart from visits with the outside world, this becomes your world. (Victor, 30s, 18-yr tariff, served 19)

As suggested here, then, coming to terms with the sentence was precipitated by the realization that the outside world was moving on in one's absence. It also meant 
acknowledging that the prison was now 'home', and the only place where life could meaningfully be led:

I'm not gonna sit here and cry. I've gotta carry on me life, so in my mind I'm just, you know, I'm doing 30. This is home now, innit. That's the way I look at it. [...] This is life now. Get used to it. Which I have. (Zubair, 20s, 29-yr tariff, served 3)

It doesn't matter where you're living, you're still living a life. Life is just the environment you're in ... and if I was on the outside, I would probably, I'd still be doing the same things, I'd still try to be learning academically. I'd still try to be forming friendships. The only real thing about prison is that, one, there's no girls, and, two, you don't get to see your family whenever you want. And those are the only two things that really I miss. (Carl, 20, 20s-yr tariff, served 1)

As suggested in the second quotation above - 'those are the only two things that I really miss' - re-framing the prison as the primary life domain required prisoners to downplay the deprivations inherent in their predicament, or to positively re-interpret their situation. Indeed, some participants compared their existence favorably to extreme alternatives ('my life could be worse, my health could be worse [...] the physical conditions that I am in could also be worse'; 'There's a lot of people in worse situations around the world so...'). The strained optimism of these rationalizations signalled the need for prisoners to try to develop a positive narrative of their current situation, and - as the external world became more distant - to deal productively with the issues that they faced: the time that lay ahead of them, their crimes, and issues of control, personal development and existential meaning. In the following sections, then, we turn to each of these domains in more detail, highlighting throughout an underlying 
shift from a form of agency that was largely regressive and reactive to one that was progressive and productive.

\section{Managing time}

O'Donnell (2014: 177) notes that: 'Despite its centrality to their lived experience, little is known about how prisoners negotiate time'. Almost all prisoners in our study who were in the early years of their sentence expressed difficulties in managing the perpetual present of their sentence, and making sense of the amount of time that they were facing in prison. When asked specifically how they thought about and handled 'time', they talked of the impossibility of getting to grips with sentences that were often as long as the number of years they had been alive, or of the psychological risks of dwelling on what lay ahead:

How do you think about your time in here?

I don't; I just don't think about it.

Do you think about day-to-day, week-to-week?

No.

Do you plan at all?

No.

Do you plan your days at all, plan your weeks at all?

No. I take days as they come and I don't want to do none of that. (Tamara, 20s, 25year tariff, served 3)

I don't ever, ever, ever think about it as a whole because as soon as I [do] I feel my head going west and I'm like 'oh no, I can't do that amount of time', and then that's 
when like the suicidal thoughts start coming into my mind. (Jackie, 20s, 22-yr tariff, served 4)

Certain phrases - 'I just take each day as it comes'; 'you take it a day at a time' - were strikingly recurrent (see Zamble 1992). Such responses spoke of a lack of capacity to conceptualize their own future, and of deep despondency: 'Tomorrow is irrelevant. Tomorrow's gonna be similar to today, so there's no point thinking about tomorrow'; 'Today's the day. If you survive it, that's another day tomorrow'.

Significantly, early-stage prisoners described the present as well as the future as endless and without hope: 'life just stops when you are behind these doors. Like it's frozen the time, basically'. Imprisonment was described as 'just existing ... You're not really living, are you?' They considered themselves 'stuck in time' - what Zamble and Porporino (1988) describe as a form of 'deep freeze' and Cope (2003: 165) reports as a form of 'suspension'. When they described how they managed time, generally they talked through a daily timetable, or mundane short-term milestones, such as the programming of television shows. Typically, these activities were described as means of 'killing time', that is, consuming an unwanted and surplus entity. The metaphor of death was also discernible in descriptions of the nature of time in this early sentence phase:

It was just killing dead time I suppose, the first [few years]... it was just dead time. You're not progressing, you're not going backwards - you're sort of stuck in limbo. You're treading water. (Gibson, 30s, 20-yr tariff, served 10) 
Terms such as 'stuck in limbo' and 'treading water' were telling. Neither connote sheer passivity as such, since they require contortion and effort. But the former indicates being stuck between two states, while the latter implies expending energy to try to counter both the flow of the current and its direction of travel, in a manner that is ultimately unsustainable.

Among participants who were further into their sentences, responses were considerably more mixed, but suggested a much stronger sense of accepting the flow of the present and actively managing the future. While some continued to describe highly limited temporal horizons, others projected ahead (or, to use O'Donnell's (2014) term, 'rescheduled') by splitting their tariff into equal sub-sentences ('I've been trying to look at it five years at a time'), or conceived of their sentence in terms of regular sporting events (such as the Olympics or the football World Cup). Most often, their conceptualizations of the sentence (what Cohen and Taylor (1972: p95) refer to as their 'subjective clock') fixated on calculations about when they might progress to lower-security prisons. Reaching the halfway point of the tariff, or having only 'single figures' remaining were major psychological milestones ('the home stretch'). Although these prisoners often could not think through the entirety of the span of time ahead of them, compared to their early-stage counterparts, they were much more able to cast themselves beyond the immediate present. Even in describing calendar years, they more often talked of the rhythm of specific sport seasons (e.g. motor racing, football), or patterns that they themselves imposed upon the months:

Gymnasium has been the most constructive thing for me because I started to train seasonally, so in winter I would bulk up, in summer I would cut up. And I started to think in seasons and just throw everything into gym, so I'd surround meself with guys that go to the gym. We'd converse. We'd cook high-protein meals, we'd go to the 
gym together. [...] So you become very focused on a period of time, and everything around your prison sentence is all shaped around that $[\ldots]$ and it's surprising just how one day merges into the next. (Bernard, 40s, 16-yr tariff, served 24)

In explaining how they passed their days - for example, through reading and study, computer games and television, and the gym - their accounts were not suffused with the sense that they were marooned in or overwhelmed by the present. Whereas early-stage prisoners found the imposition of routines unbearably repetitive, those further into their sentences customized their own routines, in ways that made prison life tolerable and predictable. Many drew on practices of faith and spirituality to tame the immediate burdens of the present and manage unwanted thoughts. Thus, one prisoner explained that the rhythm of Muslim prayer 'makes your time fly, really, because [once] you've finished one prayer, you know, it's time for your next one'. Others explained that acts of meditation helped not only to manage stress, but to construct 'moments' that existed outside institutional time:

It's given me the ability to take a moment for myself, and reflect. Five times a day I pray, and sometimes more than that. So it gives me a moment to reflect, pray, to forget about everything, [...] I feel like sort of refreshed. (Stephen, 20s, 16-yr tariff, served 8).

More significantly, as suggested here, mid-stage prisoners were much more likely than earlystage prisoners to describe time as something that could be used constructively, rather than just filled and expended (Flanagan 1981): 
One of our [religious] scholars said, “Time's like a sword. If you don't grab hold of it, it'll split you in two." And that's exactly what happens in prison. [...] We've been given time, isn't it? Prison is about time. You have a certain amount of time. That's your punishment. [...] It's very important to use time well. (Mohammed, 20s, 19-yr

\section{tariff, served 9)}

For prisoners beyond the early sentence phase, then, the present was not experienced as a form of 'stasis' or stagnation (see Wahidin 2006), in part because life was no longer considered 'on hold', in the past, or being lived elsewhere. This shift entailed a realization that effort was better spent 'thinking about what is ahead', than on reminiscence and regret for a past that was no longer salient. Once this temporal, psychological transition was made, time became less of a burden to be fought or managed, and more a resource to be harnessed.

\section{Coming to terms with the offense}

For a large proportion of participants, an essential component of adapting to their reality involved coming to terms with their offense. Prisoners who were some way into their sentences often recalled that, in their first few years of imprisonment, they had sought to deny the full implications of their crime (by engaging in various forms of offense minimization, or by 'burying' it through the use of drugs and alcohol). Many explained that they had initially felt a form of inchoate anger, reflecting a set of un-processed sentiments about what they had done and its consequences. Dealing with, and moving on from, these feelings required a broader process of 'accepting' and 'taking responsibility' for the offense: 
At first I was angry with the victim. [...] I was looking to blame him and then I went through blaming myself [...] And after time I started to say 'Do you know what, I am the problem. Let's fix the problem. [...] I have done this, this is what happened'. [...] As a result of my actions, somebody did end up dying, and I accept that. I accept my responsibility in that regard. (Stephen, 29, 16-yr tariff, served 8)

He shouldn't have died, his family shouldn't have felt the grief [...] But, at the same time, there's nothing I can do, so I can't carry this burden with me for the rest of my life because there's nothing that I can do. I can't feel sorry that I'm not in my daughter's life, I can't feel sorry that I wasn't there for my mum or my gran $[\ldots]$ when they were grieving. [...] There's nothing that I can do for [his family]. And with acceptance is when I came to terms with it. (Julius, 30s, 15-yr tariff, served 8) Do you spend a lot of time thinking about the victim and the victim's families [...]? At first you do. But I think they're the people that start having problems [...] thinking about it all the time and that. Don't get me wrong, you don't forget it. You, sort of, let it go. [...] You put it to one side and just leave it. But you don't forget it. I mean, you don't think 'oh, I killed someone. It's nothing' (Noel, 20s, 16-yr tariff, served 3)

As suggested in these quotations, 'acceptance' entailed a complex form of agency and resignation: taking moral responsibility, while also recognising the futility of being hobbled by what was now in the past. Thus, when participants described the offense as 'constantly hovering in your mind' or as 'always being there', they were invoking this form of constant presence. They could never 'come to terms' entirely with the enormity of the act of murder, and its consequences continued to preoccupy them. But by no longer suppressing their 
feelings of guilt, while finding means of self-forgiveness, they could avoid being psychologically swamped by what they had done.

Coming to terms with being a murderer also involved the management of shame. Most interviewees who were not disputing their guilt were highly remorseful about what they had done, and expressed disgust and bewilderment that they had been capable of this crime (see Irwin 2009). Those who were beyond the early sentence phase reproached themselves morally, and engaged in forms of profound existential reflection about what it meant to take someone else's life. Most strained to communicate the profound impact of such an act on their sense of self:

With murder now you'll never come to terms with it, because it's an inhuman act, just like rape is an inhuman act. But murder is something else, it's a different part of something else, it's completely different. It's not... [coughs] I don't know, I don't really know how to explain it.

Does it change your identity?

It changes who you are. Definitely [...] You lose something human inside of you once you commit a murder. You [...] lose a bit of yourself. (Benjamin, 30s, 15-yr tariff, served 14)

Somebody's dead because of me, and because of this group that I was with. So now I'm evaluating how I react to situations, $[\ldots]$ and things like that. Are you re-evaluating yourself? Your whole identity?

Yeah. I'm thinking, 'Why the hell am I in this situation. [...] Am I capable of something? [...] Like that's not me. That's not what I've been about all my whole life, 
[...] why I'm in this situation, what the hell am I? Where do I fit in society? [...] why did I allow this to happen? Why did I allow myself to do this? Why can't I read? Why am I in prison? Why is it always me? (Stephen, 20s, 16-yr tariff, served 8)

For some prisoners, this process - what Irwin (2009) calls a 'self-inventory' - was prompted by participation in victim awareness courses or prison-based therapeutic communities, or by direct meetings with relatives of their victim. For others, it derived from the rumination produced by endless hours spent alone in a cell (see Comfort 2008; Schinkel 2014).

Whichever the case, it was a key part of the process of adjusting to the sentence:

I've destroyed not just one life, like my action had the ripple effect on not just my family $[\ldots]$. Like there's a mum out there, there's a dad out there, there's brothers, sisters grieving every single day for the action that I had taken. And from the time I started looking at things from their point of view, my whole outlook has changed on my sentence and how I feel about my sentence. (Asad, 30s, 18-yr tariff, served 11)

Again, then, 'learning to live with' the offense meant no longer just 'reacting' to it, as an act in the past, through forms of anger and denial, but using it positively to turn to the future. Many interviewees described engaging in forms of self-management so as to avoid the kinds of behaviors and reactions that had led to their index offense:

It's sad that somebody had to lose their life for this to happen. But I've learnt from that [...] I mean, it was a terrible mistake. But I've never struck anybody and I deal with anger not physically, I'll walk away, I'll take time out, I will calm myself [and] think through my consequences of my actions [...] And I have developed as a coping 
strategy for me, it's almost like a little overseeing thing in my head that monitors my feelings and my emotions, and any triggers. (Ray, 50s, 15-yr tariff, served 38)

Here, prisoners were engaging in the kind of reflection and ethical self- cultivation that Foucault (1986) describes as a form of moral 'subjectivation'. As well as seeking to understand what had led to their imprisonment, they were developing their own 'code' for living, and, in doing so, re-constituting themselves as ethical agents, able to choose key aspects of personal conduct and invest these choices with moral meaning.

As part of the process of overcoming feelings of shame, interviewees who were beyond the first few years of the sentence also talked consistently about wanting to give something back to the 'younger generation' (Erikson's (1982) 'generativity'). The language of redemption and 'making amends' was recurrent (Irwin 2009). These sentiments were rooted in a sense that, in effect, two lives had been 'wasted', those of both the victim and the perpetrator:

All I can do is I can take the positives from this situation. A person of 19 years old died, you know, and I can never ever take that back. [...] The only thing I can do is change, make myself a better person, and obviously try and affect people in beneficial ways. [...] I have to make something happen, you know, like a shining star come out of something bleak and black. (Stephen, 20s, 16-yr tariff, served 8)

The last thing [the victim's mother] said to me [during an organized encounter] was she did not want two lives to be wasted, and that she wanted me to make sure that my life turned out with something good, and not waste it, you know, partly in the memory 
of her son who died that night. And it was like taking a deep breath for a first time, [...] it was like I felt some new life in my lungs. (Daniel, 30s, 18-yr tariff, served 9)

\section{Control and self-control}

Prisoners in the early stage of their sentence consistently reported feeling that they had virtually no control over their lives:

Do you feel like you have got control over your life in here?

You ain't got no control, unless you have got a set of keys.

Do you feel like you have control in any way, is there anything that you do to try and keep a bit of control for yourself?

Control my anger, that's about it. (Martin, 20s, 25-yr tariff, served 2)

Do you feel you have control over certain areas of your life in here?

You have no control over anything.

No control over anything?

Not really. You can think you have control but in the end the officers have control.

(Paul, 20s, 23-yr tariff, served 4)

To what extent do you feel that you've got control of your life in here?

Limited. It's limited because...you don't have the keys do you.

Well are there areas of your life where you do feel that you have some control? 
Yeah, course. In here, in your own mind, your health, go gym, try to keep yourself fit. But apart from that, any time they can come and say 'You're gone [to another jail]'.

\section{(Cary, 20s, 19-yr tariff, served 4)}

As indicated in these quotations, early-stage prisoners were preoccupied with the basic terms of their predicament, and interpreted 'control' in relation to the structural limits on their freedom(s). Accordingly, the absence of control was felt most keenly in relation to the general loss of liberty, and the power held over them by prison officers. Ultimately, then, these prisoners felt that their lives were primarily determined by other individuals.

The responses of participants who were further into their sentences shared many characteristics with these narratives, but exhibited a much stronger sense that key aspects of life could be self-determined. Mid- and late-stage prisoners certainly recognized that their control was in many ways circumscribed. However, they were better able to identify the specific areas of life over which they did and did not have control, and had a more expansive conception of the former:

Do you feel that you've got control of your life in here?

Not really, of course I haven't. Someone tells me when to bang up, when to shit, when to eat, so obviously I haven't, but I try and keep as much control of my life that I can. [Are there] other areas of your life where you try to retain control, or gain back some control...?

Yeah, my behaviour. [...] No one can make me mad, only I can make myself mad [...] it's up to me how I react to it, innit? (Asad, 30s, 18-yr tariff, served 11) 
Do you feel that you've got control of your life in here, or control of certain aspects of your life?

I've got control of certain aspects. [...] I've got control in my reactions and how I react to people, and how I interact with people [and] my plans for the future and getting myself prepared and ready for that. I've got certain control over my education and I've got certain control over staying healthy, and staying fit, staying positive.

(Daniel, 30s, 18-yr tariff, served 9)

As suggested above, those who were further into their sentences understood control less in relation to external constraints than the internal freedoms that were possible within the parameters of incarceration. Thus, much of the emphasis in such comments was on control of the self, both forms of conduct ('just how I act, how I behave'; 'how I think and what I do I've got complete control over') and one's essential personhood ('I have no liberty, but [...] I am in control over the person I've become. I made the person I am'). Through such comments, as Johnson and Dobrzanska (2005) also report, prisoners were acknowledging their powerlessness to control their general predicament and the futility of trying to do so:

You have said 'It is what it is' quite a few times, and it seems to be quite an important mantra for you $[\ldots]$.

Yes because I know how much time and energy I would waste on doing that, when I first come away, about things I couldn't change, and I would never be able to change. [...] You are wasting that time, when you could be using that time on something else that you could change $[\ldots]$. And that's what I've tried to do ever since, is not go over old ground that you can't work out any different to what it is. Some things are what 
they are, and you ain't never going to change it ever, [so] you have got to be able to put it to bed and move on. (Joseph, 40s, 20-yr tariff, served 22)

Here, then, we find a clear expression of a broader shift, in which our participants relinquished the unalterable past, submitted to those aspects of the present that they could not alter, and sought to build a constructive future. As we discuss below, this orientation to the future was significant, grounded in a sense of who participants wanted to become ('I think I'm in charge of my own destiny').

\section{Making the sentence meaningful and constructive}

Relatively few participants who were in the first few years of their sentence could see ways of building a life in prison, or making the sentence productive. Instead, their narratives identified the prison as a place of permanent but pointless stasis:

I wouldn't want to be doing anything meaningful for this place, but I don't know nothing, nothing constructive will help me, I think to be honest with you. Because I am still in the same place, I am still within these walls. I am not going anywhere. (Martin, 20s, 25-yr tariff, served 2)

You can't really build a life in prison. You can, sort of, get things to help you build a life when you get out. [...] You can get [qualifications] in here which will help you build a life when you get out. But I mean, while you're in jail you're, sort of, on standby. (Noel, 20s, 16-yr tariff, served 3) 
In contrast, prisoners who were beyond the early sentence phase had generally come to terms with the relocation of 'life' - at least in some senses - from the external community to the prison interior. As suggested above, for some, this meant trying to lead a life that was analogous to the one they might have led outside, by investing in education or learning new skills (see Cohen and Taylor 1972; Zamble 1992). For others, spurred by a sense of having hit 'rock bottom', it involved a more comprehensive project of change. ${ }^{10}$ Certainly, most interviewees - once they had come to terms with their conviction and sentence length wanted to 'achieve something better in my life' and make the most of their sentence, through the kinds of redemptive projects discussed above or other forms of self-improvement:

My plan is do as much education as humanly possible. Just not to waste any time while I'm in jail, basically. That's the goal. I'm here so I might as well use that time the best I can, so if I focus on education that's something that will stay with me when I finally get out and will benefit me. (Antone, 20s, 17-yr tariff, served 3)

Many interviewees expressed a commitment to a more wholesale form of personal change, describing the sentence as 'a chance to work on myself', 'see the bigger picture', and 'make myself a better person'. Since they were relatively young when sentenced, they felt a sense of loss not - as is often described (e.g. Crawley and Sparks 2006; Jewkes 2005) - for the life that they had already established, but the life that they had expected to lead, their possible selves and achievements. With few resources of identity and status from before their sentence to draw on, their orientation was to the future rather than the past. Instead of seeking to cling onto a 'respectable self' that was already established, they sought to create such a person anew. In doing so, they often invoked notions of self-discovery or reconstruction - a sense

\footnotetext{
${ }^{10}$ It was striking that, when asked how they 'built a life' in prison, most interviewees responded by talking about the construction of a new personal identity, rather than a set of social relations.
} 
that they were unearthing or developing a deeper understanding of themselves and the behavior that had led to their imprisonment ('I feel I know who I am, finally').

Those prisoners who were committed to faith practices (in particular, Islam, Christianity and Buddhism) or forms of spirituality or transcendentalism, such as yoga and meditation, reported additional ways of finding meaning in their situation or transforming it into something bearable or productive (see Eytan 2011). First, the tenets of faith fortified them to endure their sentence: several participants stated that, without their faith, they would have killed themselves rather than undergo such long periods of incarceration: 'At times it's kept me alive, it's kept me buoyant, it's kept me strong'. The term 'contentment', linked explicitly to forms of belief, highlighted an attitude of positive fatalism. This acceptance of fate, without bitterness or depression, required interviewees to believe that their predicament and suffering had some kind of wider purpose - what O’Donnell (2014) calls 'reinterpretation':

It made the verdict a lot easier to take in a sense that: 'God, you promised that you'd never leave me, and never abandon me, so just help me through this' [...] I believe that God never gives you more than you can bear. So [I] know that I'll be able to cope, I know that I'll be able to get through it. [...] I would find it hard to go through this sentence without believing in a higher purpose, without believing that there's a reason for me going through this and experiencing this. (Carl, 20s, 25-yr tariff, served 1)

Those whose beliefs did not alleviate the pains of the present referred to the motivating power of a more peaceful afterlife: 'I won't be suffering like this, so that's what keeps me motivated'. In these respects, practices of faith and spirituality helped prisoners to transcend their current state through reference to a higher spiritual and explanatory power. Second, 
these systems of belief fulfilled the need for a wider sense of meaning and purpose, a form of ideological sustenance and 'spiritual rejuvenation' (O’Donnell 2014: 259):

By trying to attribute godliness to everything and seeing the good in everything and attributing some significance to [...] the mundane, it makes it all a little less futile and a little less depressing. [...] It's a way of coping. It gives you some clarity and a sense of purpose. [...] I've always had these views but I'm conscious that as a result of having these views I've been able to get through this whole ordeal much more positively than perhaps I would have otherwise. (Dan, 20s, 15-yr tariff, served 3)

Third, religion provided answers to the kinds of existential questions described in previous sections. For prisoners who were interrogating the meaning of life, death and humanity, it provided some parameters of thought and philosophical perspective:

I became a born-again Christian when I was within the sixth year [of my sentence]. And there's a lot of growing involved in that, and a lot of learning. I feel like that's helped me to question life and the value of life, the value of my life, love, relationships, my attitude towards people who in the past I've disliked or have even to some degree had hatred for. (Alan, 30s, 18-yr tariff, served 11)

Finally, faith ideologies offered a hook for moral transformation and identity change. As explained mainly by interviewees who were further into their sentences, it showed them how to be other-oriented ('you actually have compassion and awareness of the world and people around you') and guided those who felt adrift from their humanity 'how to be a normal decent human being'. 


\section{Concluding Comments}

In Structure, Agency and the Internal Conversation, Margaret Archer (2003) seeks to specify the different modes of reflexivity - that is, 'our power to deliberate internally upon what to do in situations that [are] not of our making (p342) - that mediate between agents and the objective structures they subjectively encounter. Archer argues that, through forms of 'internal conversation' or interior dialogue, most people pursue practices and projects that are consistent with their 'ultimate concerns'. The exceptions to this are what Archer calls 'fractured reflexives', people who exist in a state of disorientation about these priorities and how to realise them. Such individuals either hold almost no internal dialogue at all, or engage in forms of self-talk which provide them 'with no instrumental guidance about what to do in practice' (p299). Their internal conversations are expressive, such that they merely dwell emotionally on their condition rather than act purposefully in pursuit of a goal. While some reflect nostalgically on a past that no longer provides a guide to action - either because of discontinuity of social circumstances, or because of some kind of profound personal change, such as serious illness or marital breakdown - others 'grasp in desperation at unrealistic projects' (p303). Whichever the case, lacking the kind of 'strict personal identity' which enables the formation of personal projects, they are 'passive agents', whose subjectivity makes no difference to the play of objective circumstances upon them' (p299).

A striking attribute of fractured reflexives, and a reflection of their agential passivity, is their tendency to 'take each day as it comes' (p314) or 'just go with life' (p330). Similarly, in the 2012 elaboration of her argument, she describes the 'expressive reflexive' (a sub-type of the fractured reflexive) as exercising agency 'solely in relation to the present moment and current 
circumstances, rather than assuming any reflexive governance over the shape of their lives' (Archer 2012: 250). Swamped by his or her problems, the expressive reflexive lives life in a constant, episodic 'present', with decisions based on 'gut feelings' rather than an interior dialogue directed towards the future.

Here, then, Archer's account is striking in its resonance with our analysis of early-stage longterm prisoners. As we have explained, such prisoners were defined primarily by the shock of being in a situation that was both unexpected and extreme. This situation had two main components: first, a profound incongruity between the prisoner's self-conception and the unexpected reality that he or she now encountered; second, the psychic burden of having been involved in a murder, with its accompanying shame, and/or the trauma of confronting a life-bending prison sentence. While contextual dislocation left these prisoners without a set of tacit guidelines for knowing how to 'go on', the sheer difficulty of confronting both their offence and their penal predicament inhibited them from engaging in forms of internal deliberation and future-oriented life-building. It also meant that their agency was not simply passive, but also reactive. Energy was committed to managing immediate forms of emotion (such as anger, shock and trauma), as well as seeking to deny aspects of their situation that they could not realistically influence (i.e. their basic state of being incarcerated). At the same time, they felt themselves to have little control over their daily existence and longer-term futures within the prison. In this respect, despite their emotional agitation, they were largely passive in the context of their everyday condition:

The first two years ... I just didn't know whether I was coming or going, you know. It was just letting my circumstances lead me, rather than taking control of what I'm doing. (Casper, 25, 25-yr tariff, served 3) 
However, these patterns of thought and action were not static. Participants who were further into their sentences had generally come to accept their predicament, worked out which areas of their lives they could and could not control, and begun to find purpose and meaning in their lives. Their focus was less on the past than the future, and their use of the present was constructive rather than merely depletive. Despite - and in some ways because of - their overarching stoicism with regard to their general circumstances, in their daily practices, they exhibited a form of productive agency, in which they sought to make the most of a situation that was not of their choosing, but from which they believed they could derive some personal value. Within the prison's structural cocoon, then, they were agentically active.

At this stage, then, the prisoner resembles Archer's 'meta-reflexive', divorced from the behavioural repertoire set out by their past, and seeking a new modus vivendi, driven by some kind of cause, vocation or ideal. Just as our later-stage participants were preoccupied with existential introspection, Archer describes meta-reflexives as highly self-monitoring, engaged in an ongoing internal conversation about the self. For our participants, it was the profound rupture of the sentence that eventually generated this search for self-understanding and meaning, along with a profound alienation from the self resulting from involvement in an act of murder. It is significant that this quest was often resolved through spiritual or religious practices, or a focus on personal ethics, for these are among the few cultural resources that are available in the context of imprisonment. As Archer notes, 'certain intentional human activities, like private prayer, can never be the objects of structural and cultural constraints' (2003: 8). The relevance of her framework is thus made apparent: long-term imprisonment, involves a decisive dislocation of agent from context, and brings into particularly sharp relief the dynamics of reflexivity, action and constraint. 
For our purposes, the most helpful metaphor is tidal. Prisoners in earlier sentence stages were in effect treading water, being carried by the tide of the sentence or were seeking to swim against it. Those further on had come to accept that they could not escape the water, or the direction of its flow. They were swimming with the tide, rather than against it, using its energy to their advantage. In this regard, our findings are consistent with O'Donnell's concept of 'acceptance', as distinct from capitulation: 'yielding to rather than opposing the flow of life' (Tolle 2005: 171, cited in O'Donnell 2014: 252), with a 'determination not to struggle in a futile fashion against that which cannot be overcome, matched by an equal determination not to give internal assent to unacceptable circumstances'. This process of acceptance required many participants to engage in a form of psychic splitting, suppressing feelings of frustration and resentment about their conviction or sentence length in order to adjust to an unchangeable long-term reality (what Schinkel (2014) describes as 'copingacceptance', and we would call the 'adaptive imperative'). To psychologically survive the sentence, let alone glean something from it, necessitated that sentiments of bitterness and desperation were set aside.

While the adaptive patterns that we have described did not hold across all participants, they applied very consistently, virtually regardless of other variables. It seems highly plausible that the nature of both the offense of murder and the exceptionally long sentences that result have a more powerful determining influence than would be found among other prisoner groups. Imported distinctions - apart from those relating to gender, and, in particular, the relevance of trauma and abuse to the lives of our female interviewees (see XXXX) - appear to be more or less flattened by the sheer heft of the act and the severity of the sanction that follows. Our findings therefore call into question the tendency within prison sociology to 
consider offense type somewhat irrelevant to prisoner adaptation - matters of law or psychology, rather than key determinants of the prison experience.

Our study is not without methodological limitations. Not least, it is a cross-sectional rather than longitudinal research design. ${ }^{11}$ While much of the data on which the article builds comes from recollections of those further into their sentence about earlier periods, such reflections are no substitute for a more dynamic analysis. We cannot rule out the possibility that the nature of long-term imprisonment, and of those sentenced to the terms in which we are interested, have changed in ways that might threaten our conclusions, although the consistencies between the accounts of participants at different sentence stages gives us confidence that this is not the case. As we also note above, the fact that prisoners who are deemed to be suffering acute mental health problems are transferred to secure psychiatric hospitals means that our exclusively prison-based sample will exclude those who cope least well with their sentences. The implication of this is that our article provides an account only of how those prisoners who do, in fact, cope manage to do so, rather than an account of how all prisoners who are given such sentences respond to their predicament.

It is beyond the scope of the study to make firm statements about the post-release effects of the adaptive patterns we have identified (although see Liem and Kunst 2013; Grounds 2005). Notably, though, Archer comments that 'since meta-reflexives can rarely be eremitic, though the most important part of themselves may be vested in activities such as lone writing or solitary prayer, their ideal of a holistically integrated life $[\ldots]$ condemns them to life-long frustration as social utopians' (2003: 353). The existence of the long-term prisoner can get close to that of the religious recluse, and, while within the prison, a 'holistically integrated

\footnotetext{
${ }^{11}$ Our intention, however, is to apply for further funding in order to conduct follow-up interviews with the original sample every five or six years.
} 
life', organised around faith or personal idealism may be achievable, outside this context (i.e. post-release), such an orientation to the world may - as Archer suggests - lead to deep disappointment. In many respects, though, when men and women are spending decades in prison (and a greater proportion of their life in prison than in the community), it is sufficient to study their in-prison experiences without reference to later outcomes. The pains they experience, the means by which they cope, and the lives they try to build matter regardless.

\section{References}

Archer, M. (2003) Structure, Agency and the Internal Conversation. Cambridge, CUP.

Banister, P.A., Smith, F.V., Heskin, K.J. \& Bolton, N. (1973). Psychological correlates of long-term imprisonment: I Cognitive variables. British Journal of Criminology, 13, 312-323.

Cohen, S. \& Taylor, L. (1972). Psychological survival: The experience of long-term imprisonment. Harmondsworth: Penguin.

Comfort, M. (2008). 'The best seven years I could'a done': The reconstruction of imprisonment as rehabilitation' in P. Carlen (Ed.) Imaginary Penalities (pp. 252-274). Cullompton: Willan.

Cope, N. (2003). 'It's no time or high time': Young offenders' experiences of time and drug use in prison. The Howard Journal of Criminal Justice, 42, 158-175.

Crawley, E. \& Sparks, R. (2006). 'Is there life after imprisonment?' How elderly men talk about imprisonment and release. Criminology and Criminal Justice, 6, 63-82 
Crewe, B. (2011). Depth, weight, tightness: Revisiting the pains of imprisonment. Punishment \& Society, 13, 509-529.

Crewe, B., Liebling, A., Padfield, N., \& Virgo, G. (2015). Joint enterprise: The implications of an unfair and unclear law. Criminal Law Review, 4: 249-266.

Erikson, E. (1982). The Life Cycle Completed: A Review. New York/London: Norton.

Eytan, E. (2011). Religion and mental health during incarceration: A systematic literature review. Psychiatric Quarterly, 82, 287-95.

Flanagan, T. (1981). Dealing with long-term confinement: Adaptive strategies and perspectives among long-term prisoners. Criminal Justice and Behavior, 8, 201-222

Foucault, M. (1986). The care of the self: Volume 3 of the history of sexuality (R. Hurley, Trans.). New York: Pantheon Books.

Grounds, A. (2005). Understanding the effects of wrongful imprisonment. Crime and Justice, $32,1-58$.

Hollway, W. \& Jefferson, T. (2000). Doing qualitative research differently: Free association, narrative and the interview method. Thousand Oaks: Sage Publications.

Irwin, J. (2009). Lifers: Seeking Redemption in Prison. New York and London: Routledge. 
Jamieson, R. \& Grounds, A. (2005). Release and adjustment: Perspectives from studies of wrongly convicted and politically motivated prisoners. In A. Liebling and S. Maruna (Eds.), The effects of imprisonment (pp. 33-65). Cullompton: Willan.

Jewkes, Y. (2005). Loss, liminality and the life sentence: Managing identity through a disrupted lifecourse'. In A. Liebling and S. Maruna (Eds.), The effects of imprisonment (pp.366-388). Cullompton: Willan.

Johnson, R. \& Dobrzanska, A. (2005). Mature coping among life-sentenced inmates: An exploratory study of adjustment dynamics. Corrections Compendium, 30(6):8-9, 36-8.

Johnson, R. \& McGunigall-Smith, S. (2008). Life without parole, America's other death penalty. The Prison Journal, 88, 328-346.

Kazemian, L. \& Travis, J. (2015). Imperative for inclusion of long termers and lifers in research and policy. Criminology \& Public Policy, 14, 355-395.

Leigey, M. \& Ryder, M. (2015). The pains of permanent imprisonment: Examining perceptions of confinement among older life without parole inmates. International Journal of Offender Therapy and Comparative Criminology, 59, 726-742.

Liebling, A. (2014). Moral and philosophical problems of long-term imprisonment. Studies in Christian Ethics, 1-12. 
Liebling, A. and Maruna, S. (Eds.).The Effects of Imprisonment. Cullompton: Willan.

Liem, M. and Kunst, M. (2013). Is there a recognizable post-incarceration syndrome among released 'lifers'? International Journal of Law and Psychiatry, 36, 333-337.

Mackenzie, D.L. \& Goodstein, L. (1985). Long-term incarceration impacts and characteristics of long-term offenders: an empirical analysis. Criminal Justice and Behavior, $12,395-414$.

McAdams, D. (1988). Power, intimacy, and the life story: Personological inquiries into identity. New York: Guilford Press.

O’Donnell, I. (2014) Prisoners, Solitude, and Time. Oxford: Clarendon, OUP.

Rasch, W. (1981). The effects of indeterminate detention: A study of men sentenced to life imprisonment. International Journal of Law and Psychiatry, 4, 417-431.

Rhodes, L.A. (2004). Total Confinement: Madness and Reason in the Maximum Security Prison. Berkeley and Los Angeles: University of California Press Ltd.

Richards, B. (1978). Experience of long-term imprisonment: An exploratory investigation. British Journal of Criminology, 18, 162-169.

Sapsford, R. (1983). Life sentence prisoners: Reaction, response and change. Milton Keynes: Open University Press. 
Schinkel, M. (2014) Being imprisoned: Punishment, adaptation and desistance. Basingstoke: Palgrave.

Toch, H. (2010) 'I am not now who I used to be then': Risk assessment and the maturation of long-term prison inmates. The Prison Journal. 90, 4-11.

Wahidin, A. (2006). Time and the prison experience. Sociological Research Online, 11(1). Retrieved from http://www.socresonline.org.uk/11/1/wahidin.html

Walker, S \& Worrall, A (2000). Life as a woman: The gendered pains of indeterminate imprisonment. Prison Service Journal, 132, 27-37

Zamble, E. (1992). Behaviour and adaptation in long-term prison inmates: Descriptive longitudinal results. Criminal Justice and Behavior, 19, 409-425.

Zamble, E. \& Porporino, F. (1988). Coping, behavior, and adaptation in prison inmates. New York: Springer-Verlag. 